Azevedo, F.F.; Chicico, F.J. Turismo de base local no distrito de Dondo (Moçambique): discutindo fatores de sustentabilidade. Revista Brasileira de Ecoturismo, São Paulo, v.6, n.2, mai/jul-2013, pp.458-481.

\title{
Turismo de base local no distrito de Dondo (Moçambique): discutindo fatores de sustentabilidade
}

\author{
Locally-based tourism in the district of Dondo (Mozambique): \\ discussing sustainability factors
}

Francisco Fransualdo Azevedo, Felicidade da Juliana Chicico

\begin{abstract}
RESUMO
O atual debate sobre desenvolvimento rural focaliza a abordagem territorial, reconhecendo o caráter multifuncional do espaço rural. Enfatiza o aproveitamento das forças endógenas, a necessidade de implementação de políticas que valorizem as especificidades locais, a participação dos atores sociais na dinamização e revitalização do espaço rural. É neste contexto que este estudo trata do turismo de base local como indutor de desenvolvimento rural, traduzindo-se numa análise da realidade e das potencialidades no distrito de Dondo em Moçambique. Nele se propôs analisar as potencialidades para a implantação do turismo de base local no Distrito de Dondo, avaliando até que ponto a realidade local possibilita a inclusão da comunidade na gestão dos recursos turísticos locais. Os resultados da pesquisa mostram que o distrito de Dondo apresenta um potencial para implementação de um modelo de desenvolvimento de turismo de base local, pois ele é rico em recursos naturais e culturais, beneficia-se de uma boa rede de acessibilidade no contexto do mercado da região, a população vive segundo os seus hábitos e costumes e valorizam a sua identidade. Constata-se também um certo nível de cooperação entre os membros da comunidade, fato que se observa através do nível de participação da comunidade em associações, cooperativas e núcleos atuando em áreas como agricultura, pesca, extração de carvão vegetal, ambiente, educação cívica, etc. Apesar de obstáculos como inexistência de políticas e planos locais para o desenvolvimento do turismo, falta de consciência em relação ao turismo, insuficiência em infra-estruturas básicas, bem como em equipamentos e meios de apoio ao turismo, denota-se que estes problemas podem ser solucionados por meio de um comprometimento tanto do setor público, como da comunidade através de uma planificação conjunta e participativa.
\end{abstract}

PALAVRAS-CHAVE: Desenvolvimento Rural; Turismo de Base Local; Fatores de Sustentabilidade; Regiões Periféricas 


\begin{abstract}
The current debate on rural development focuses on the territorial approach, recognizing the multifunctional character of rural areas. It also emphasizes the use of indigenous forces, the need to implement policies that improve local specificities, as well as the participation of social actors in fostering and revitalizing rural areas. In this context, this study focuses on locally-based tourism as a facilitator of rural development, analyzing the reality and potential of the district of Dondo in Mozambique. It aims at analyzing the potential for the development of locally-based tourism in the district of Dondo, assessing the extent to which local reality enables the inclusion of the community in the management of local tourism resources. The investigation showed the inclusion of tourism on a local basis in the current context of rural development; The results show that the district of Dondo has a potential for implementing a model of tourism development on a local basis, since it is rich in natural and cultural resources, benefits from a good network accessibility in the context of market region, the population live according to their habits and customs and value their identity. There has been a certain level of cooperation between community members, a fact which is observed through the level of community participation in associations, cooperatives and centers working in areas such as agriculture, fishing, extraction of coal, environment, civic education, etc. Despite obstacles such as lack of local policies and plans for tourism development, lack of awareness in relation to tourism, lack of basic infrastructure, as well as equipment and facilities to support tourism, the investigation shows that these problems can be solved through a commitment of both public sectors and the community through a joint planning and participation.
\end{abstract}

KEYWORDS: Rural Development; Local Tourism; Sustainability Factors; Peripheral Regions.

\title{
Introdução
}

Esta análise parte do princípio de que o turismo de base local se constitui num dos possíveis meios para induzir uma nova dinâmica no espaço rural, visto que o mesmo é tido como um canal para a revalorização dos recursos naturais e culturais, bem como do modo de vida dos lugares.

Trata-se de uma análise critica da realidade do turismo no distrito de Dondo Moçambique, com base nas dimensões de análise estabelecida para este trabalho. Convém ressaltar que estas dimensões foram definidas em função dos princípios de sustentabilidade, pois, para que o TBL propicie resultados positivos é necessário que este seja orientado pelos princípios de sustentabilidade.

Analisa-se as potencialidades com vistas à implantação do turismo de base local no Distrito de Dondo, avaliando-se até que ponto a realidade local possibilita a inclusão da comunidade na gestão dos recursos turísticos locais. Nesse contexto, busca-se mostrar a inserção do turismo de base local no atual contexto de desenvolvimento rural. 
Ademais, buscar-se-á identificar e organizar sistematicamente os fatores que condicionam a implementação do turismo de base local na área estudada, verificando -se até que ponto a realidade empírica corresponde aos condicionantes identificados, mostrando como o turismo de base local pode ser melhor incentivado.

Em alguns países da África Austral como África do Sul, Angola, Kénia, Namíbia, também tem se verificado a ocorrência de turismo de base local, verificando-se experiências isoladas, mas que já despertam a atenção do poder público para a criação de instrumentos que orientam a prática do mesmo. Entretanto, nem todas as regiões rurais têm aproveitado a atividade em prol de seu desenvolvimento, como é o caso do distrito de Dondo-Moçambique.

Como se pode observar na Figura 1, Dondo é um distrito que se localiza em Moçambique, especificamente no "Centro-Leste da província de Sofala, limitando-se ao Norte com o Distrito de Muanza, a Oeste com o Distrito de Nhamatanha (sic) Nhamatanda, a Sul com o Distrito de Buzi e Cidade da Beira e a Este pelo Oceano Indico" (MAE, 2005, p. 2).

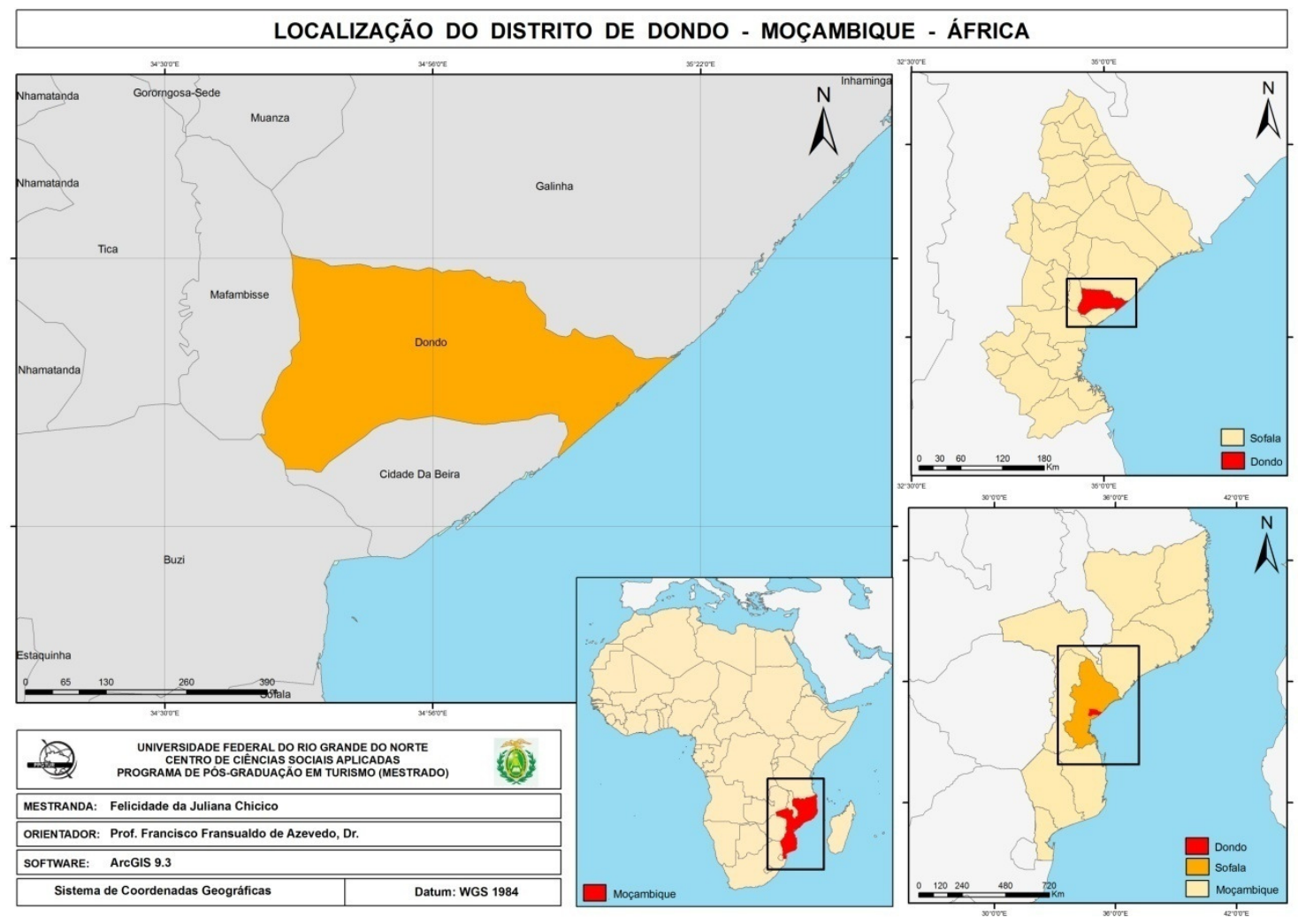

Figura 1: Localização da Área de estudo. Fonte: WGS, 1984.

Figure 1: Location of Study Area. Source: WGS, 1984.

É importante destacar que Moçambique é um país situado na parte sul da costa Oriental Africana, e enquadra-se no grupo dos países considerados periféricos no contexto socioeconômico mundial, sendo a agricultura uma das atividades considera- 
Turismo de base local no distrito de Dondo (Moçambique): discutindo fatores de sustentabilidade

das básicas para o desenvolvimento do país devido ao alto potencial agrícola. Mas pela diversidade natural e cultural que possui o turismo também tem sido visto como atividade estratégica para a melhoria da qualidade de vida da população se implementado de forma planejada e com envolvimento da população no processo de planejamento (MOÇAMBIQUE, 2006).

Dondo é um distrito costeiro rico em recursos naturais, culturais e com grande potencial agrário, conforme o Ministério de Administração Estatal - MAE (2005, p.15), "a proximidade da cidade da Beira, a integração no corredor da Beira e o acesso fácil a província vizinha ${ }^{1}$ e mesmo ao Zimbabwe, possibilita ao distrito uma boa integração a rede de mercados".

\section{A inserção do Turismo de Base Local no atual contexto do desenvolvimento territorial rural}

O atual debate sobre desenvolvimento rural focaliza a abordagem territorial, reconhecendo o caráter multifuncional do espaço rural. Enfatiza o aproveitamento das forças endógenas, a necessidade de implementação de políticas que valorizem as especificidades locais, a participação dos atores sociais na dinamização e revitalização do espaço rural. É neste contexto que o turismo entra como um dos meios para induzir uma nova dinâmica ao espaço rural, visto que a atividade é tida como um canal para a revalorização dos recursos naturais e culturais, bem como do modo de vida rural

A revolução industrial trouxe grandes mudanças tecnológicas que teve um forte impacto sobre o processo produtivo, em nível econômico e social, tendo iniciado na Inglaterra meados de século XVIII e espalhando-se pelo mundo a partir do século XIX e os seus efeitos se registram até os dias atuais (BURNS, 1995). Transformações como o avanço tecnológico no que se refere aos meios e técnicas de produção, meios de transporte e comunicações; rápido crescimento econômico; substituição do trabaIho humano pelas máquinas; novas relações entre as nações e o fenômeno cultura de massa impostos pelo capital que emergiu nesse período; redução da população rural devido ao deslocamento para os centros urbanos em busca de trabalho, a baixa condição de vida no espaço rural, comparada a do meio urbano na época, foram algumas das razões que deixaram o meio rural aquém dos avanços técnicos verificados no meio urbano (BURNS, 1995; AMAP, 2004).

Posteriormente problemas como mudanças climáticas, empobrecimento dos solos, degradação de infraestruturas, dificuldades de colocação dos produtos no mercado aliado ao desemprego nas zonas rurais, constituíram fatores que levaram os países do primeiro mundo como Estados Unidos da América (EUA), Inglaterra, Itália, Espanha, França a apostarem em políticas públicas que estimulassem o desenvolvimento no meio rural, por meio de incentivos a prática de atividades que pudessem proporcionar a multifuncionalidade, o resgate e a revalorização da cultura, do meio ambiente, assim como, do modo de vida rural (CANDIOTTO, 2010).

O turismo é uma atividade que tem sido apontada como estratégica para impulsionar o desenvolvimento tanto de nações hegemônicas, bem como das nações peri- 
féricas. Dentro do contexto do desenvolvimento rural, assim como, das novas tendências no turismo, têm surgido novos modelos de turismo, centrados na busca por práticas turísticas alternativas ${ }^{2}$ sustentadas por princípios de sustentabilidade, e um deles é o Turismo de Base Local (TBL).

Por se constituir num modelo centrado no aproveitamento da diversidade territorial de forma inclusiva, o TBL mostra-se como um veículo efetivo para a melhoria da qualidade de vida da população rural de forma participativa e integrada, uma vez que a comunidade também se responsabiliza, tanto pela concepção, como pela gestão da atividade turística (CORIOLANO, 2005).

Conforme Silva, Ramiro e Teixeira (2009), este modelo tem as suas premissas baseadas na autogestão, no associativismo ou cooperativismo, na valorização da cultura local, e principalmente no protagonismo das comunidades locais, visando à apropriação, por parte destas, dos benefícios advindos do desenvolvimento do setor.

Assim, percebe-se que o TBL é um modelo de gestão de turismo que vai de encontro com a atual perspectiva do desenvolvimento rural, visto que este possibilita a inclusão da população rural no desenvolvimento da atividade turística, expressando suas idéias e receios, identificando suas prioridades, suas necessidades, interesses e as formas pelas quais esperam se beneficiar, traduzindo-se no processo democrático e solidário. Carvalho (2007) acrescenta ainda, que o TBL mobiliza a comunidade na luta por seus direitos contra grandes empreendedores da indústria do turismo de massa, quando a ocupação de seu território por estes ameaça a qualidade de vida e as tradições da população local.

As tendências atuais do mercado turístico têm aberto um espaço para a ascensão de iniciativas de turismo de base local, pois os turistas estão cada vez mais exigentes e mais conscientizados em relação à necessidade de conservar o meio ambiente, buscam por experiências originais com maior aproximação a natureza e a cultura local e, a necessidade de fuga do estresse da vida urbana faz do espaço rural um destino eleito para visitar. Fatos que proporcionam oportunidades para as comunidades rurais optarem pelo TBL e por via disso melhorar a sua qualidade de vida (CAMPANHOLA; SILVA, 1999).

Sob o ponto de vista da inovação, o turismo de base local inserido na cadeia de produção do meio rural, pode se constituir num propulsor do desenvolvimento local, através da incorporação de novos conhecimentos e mudança nas técnicas produtivas e nas formas organizacionais (FALCÃO et. al., 2009).

Neste contexto, o desenvolvimento independentemente da sua acepção espacial (rural ou urbano) exige consideração simultânea das diversas dimensões constituintes das relações sociais (cultura, economia, política) e, também do espaço natural e social, significa o desenvolvimento das potencialidades humanas e a consolidação pela cidadania.

Assim, o individuo em vez de objeto, torna-se o sujeito e protagonista real no processo de desenvolvimento, ele se insere como um agente livre para promover a melhoria de sua qualidade de vida. O desenvolvimento na escala humana, ou seja, na 
Turismo de base local no distrito de Dondo (Moçambique): discutindo fatores de sustentabilidade

perspectiva do sujeito, requer a consideração das necessidades humanas, a autodependência e articulações orgânicas ${ }^{3}$ baseadas nas especificidades locais. No entanto, tal protagonismo só é possível mediante o processo de democratização que permite uma participação direta e ativa do indivíduo e que resulte num modelo de atuação de baixo para cima capaz de refletir as necessidades reais dos mesmos (MAX-NIFF, 1998).

Desta forma, percebe-se que o discurso sobre o TBL como um dos veículos para o desenvolvimento rural, à luz dos preceitos do desenvolvimento na perspectiva do sujeito, bem como dos principios de sustentabilidade, convergem para um posicionamento onde a liberdade das pessoas agindo individualmente e coletivamente, e a satisfação das necessidades humanas fundamentais são tidas como motor fundamental para a melhoria da qualidade de vida dos mesmos.

\section{O turismo de base local na perspectiva da sustentabilidade em Dondo (Moçambique): discutindo dimensões}

Esta análise será feita sob um enfoque das distintas dimensões da sustentabilidade, a saber: político-institucional, sustentabilidade ambiental, sustentabilidade social, sustentabilidade cultural, sustentabilidade econômica e sustentabilidade espacial (Quadro 1, próxima página).

Neste ponto foram observados aspectos relacionados à governança, como os órgãos e instrumentos de gestão do destino, nomeadamente políticas, programas e planos, além de instrumentos legais específicos ao turismo e outros instrumentos que auxiliam o desenvolvimento da atividade.

Castells (2001) afirma que o poder público não pode ficar a parte do turismo, uma vez que este setor é tido como propulsor da economia, que valoriza a cultura e cria a integração entre países e entre outros benefícios que advém da prática.

Riveros e Blanco (2003) acrescentam ainda, que, para que o turismo se converta numa alternativa de desenvolvimento para as comunidades locais e contribua efetivamente para a revalorização do espaço rural, é necessário que ele seja bem planificado, executado e controlado.

O turismo em Moçabimque é tido como um setor estratégico para o desenvolvimento do país, em 2001 foi constituído o Ministério de Turismo o maior órgão público de tutela da atividade no país (MITUR, 2004). Desde 1994 que o governo tem implementado várias políticas setoriais e legislação, com o fim de estimular o desenvolvimento da atividade no país, destacando-se a Lei do turismo (2004); Política de Turismo e Estratégia de sua Implementação (2003); Plano Estratégico de Desenvolvimento de Turismo em Moçambique (2004); Política Nacional de florestas e Fauna Bravia (1995); Lei de Fauna Bravia (1999); Lei de Terras (1997); Programa Nacional de Gestão Ambiental (1995), Lei de quadro ambiental (1997); Lei de pescas (1990), Lei de Investimento, etc. Existem também diversos programas e planos para reativação do turismo em unidades de conservação, nas zonas costeiras e no interior do país, bem como, busca de investimentos para o setor. 
Quadro 1: dimensões de análise para implementação do Turismo de Base Local no distrito de Dondo (Moçambique). Fonte: Dados da pesquisa (2012).

Table 1: dimensions of analysis for the implementation of locally-based tourism in Dondo district (Mozambique). Source: survey data (2012).

\begin{tabular}{|c|c|}
\hline Dimensões de Análise & $\begin{array}{c}\text { Fatores para Implementação Turismo de Base Local } \\
\text { analisados }\end{array}$ \\
\hline Aspectos Políticos Institucionais & Governança \\
\hline \multirow{3}{*}{ Sustentabilidade Ecológica } & Recursos turísticos \\
\hline & Atrativos turísticos \\
\hline & Conservação e Preservação do meio ambiente \\
\hline \multirow{8}{*}{ Sustentabilidade Social } & Rede de relações sociais \\
\hline & Participação comunitária \\
\hline & Mão de obra \\
\hline & empregabilidade \\
\hline & Infraestrutura básica \\
\hline & Qualificação do pessoal \\
\hline & Governança \\
\hline & Assistência aos agricultores \\
\hline \multirow{4}{*}{ Sustentabilidade cultural } & Participação comunitária \\
\hline & autenticidade \\
\hline & Consciência social e pública sobre identidade local \\
\hline & Inserção local e regional \\
\hline \multirow{9}{*}{ Sustentabilidade econômica } & Experiência turística \\
\hline & Demanda turística \\
\hline & Inserção local e regional \\
\hline & Perfil dos provedores do produto \\
\hline & rentabilidade \\
\hline & Permanência do turista \\
\hline & Sazonabilidade \\
\hline & Marketing responsável \\
\hline & Empregabilidade \\
\hline \multirow{5}{*}{ Sustentabilidade Espacial } & Equipamentos turísticos \\
\hline & Entretenimento e lazer \\
\hline & Meios de apoio ao turismo \\
\hline & Acesso \\
\hline & Arquitetura \\
\hline
\end{tabular}




\section{Dimensão político-institucional}

Para os gestores de turismo (GT) a contribuição do turismo para a economia do país ainda é baixa, desde 2002 que o turismo vinha contribuindo com 1,5\% no PIB de Moçambique, tendo se verificado um aumento de 1\% em 2010. Prevê-se que a contribuição do setor no PIB do país, ultrapasse os atuais 2,5\% até 2013. Até ao momento atual, maior parte do esforço do governo tem sido canalizado para as áreas de conservação e zonas costeiras, sendo o principal foco as áreas litorâneas.

No distrito de Dondo a gestão e regulamentação da atividade é feita em nível central pelo Ministério de turismo, considerando que a gestão pública em Moçambique segue a abordagem de baixo para cima (botton/up), ao nível do distrito é feita pelo governo distrital através dos Serviços de Atividades Econômicas em coordenação com a Direção Provincial de Turismo de Sofala.

A atividade no distrito é regulamentada pelos documentos acima referenciados e, não existe ainda nenhuma política, programa ou plano em nível local para o desenvolvimento do turismo. De acordo com os gestores do turismo (GTs) no distrito, o interesse do governo local pelo turismo é recente (2010), as atenções estavam mais direcionadas para as unidades de conservação, sendo maior alvo das atenções e ao mesmo tempo, o responsável por maior parte da receita do turismo na província o Parque Nacional de Gorongosa.

Entretanto, para que o turismo contribua significativamente na melhoria da qualidade de vida das comunidades no distrito de Dondo, há necessidade de um planejamento em nível local, assim como, a concepção de instrumentos que possam orientar a execução do turismo localmente, no que se refere a este aspecto Graziano da Silva et. al (1997), enfatiza a necessidade da participação do Estado no desenvolvimento do turismo no meio rural, através de uma planificação que possibilite o desenvolvimento sustentável, direcionando-se a atenção para as questões relacionadas aos cuidados com o meio ambiente, preservação da cultura, bem como, para a qualificação da mão de obra.

Seguindo o mesmo raciocínio, Verbole (2002) acrescenta que o poder público a nível local, na função de mediador e promotor do processo de desenvolvimento do turismo localmente, deve buscar a integração de todos os setores, uma vez que a cadeia de negócio do TBL, como em qualquer outra modalidade ou modelo de desenvolvimento de turismo, abarca diversas atividades produtivas ligados a outros setores de atividade.

Os gestores turísticos referem ainda, que devido ao aumento do fluxo de turistas no distrito e do interesse de investidores pelas áreas com potencial para o turismo no distrito, o governo local está trabalhando para estimular a prática do turismo. Atualmente tem na "manga" o projeto para reativação do complexo turístico de Sengo, que atualmente encontra-se totalmente destruída por causa da guerra civil.

Vale lembrar a que o poder público não pode ficar a parte do turismo, uma vez que este setor é tido como propulsor da economia, que valoriza a cultura e cria a integração entre países e entre outros benefícios que advém da prática e, o Estado é o 
agente cujo uma das atribuições é a planificação do desenvolvimento com base nas diversas alternativas que as atividades produtivas oferecem (CASTELLS, 2001).

Posto isto, para que o turismo seja proveitoso para a população do distrito, inicialmente o governo deve adotar uma postura comprometida com o bem estar da comunidade local, buscando por modelos de desenvolvimento de turismo que maximizam as vantagens e minimização as desvantagens do turismo.

Geralmente, a motivação do governo local pelo turismo está orientada para os aspectos econômicos, pois em nenhum momento fez-se menção a projeções para a própria comunidade assumir-se como provedora do produto turístico, em vez de se esperar pelo investidor externo como "o salvador da pátria".

Portanto para que o TBL seja implementado no distrito, há uma necessidade de reorientação dos princípios dos órgãos públicos no que se refere a escolha do turismo que se quer para o distrito, a realização de um planejamento estratégico alicerçados nos princípios de sustentabilidade, e implementação de programas de conscientização e capacitação em relação ao turismo. Como diz Castells (2001), o país ou região que opta pelo turismo como vetor para o desenvolvimento deve preparar-se para os impactos inerentes a prática da atividade e sugere como atividade primária, a definição de uma política turística que se incumbe inicialmente de educar a comunidade para a prática do turismo.

\section{Dimensão da sustentabilidade ecológica e espacial}

Nesta análise tomaram-se em consideração os seguintes fatores: recursos turísticos, atrativos turísticos e, conservação e preservação do meio ambiente, equipamentos turísticos, meios de apoio ao turismo, entretenimento e lazer, arquitetura e lazer.

Dondo é um distrito costeiro rico em recursos naturais, culturais e com grande potencial agrário, conforme o Ministério de Administração Estatal - MAE (2005, p.15). Além disso, "a proximidade da cidade da Beira, a integração no corredor da Beira e o acesso fácil a província vizinha ${ }^{4}$ e mesmo ao Zimbabwe, possibilita ao distrito uma boa integração a rede de mercados". O acesso ao distrito para fins turísticos é feito por meio rodoviário através da Estrada Nacional № 1e №6 e, pelo meio aéreo através do Aeroporto Internacional da Beira e do Aeroporto Nacional de Chimoio. Como se pode notar, a acessibilidade do distrito se constitui num grande diferencial para atração como captação dos fluxos turísticos na região.

O Plano Estratégico para o Desenvolvimento do Turismo (2004-2013) - PEDTM (2004-2013) classifica esta região como uma Área Prioritária de Investimento em Turismo (APIT) do tipo $A / B^{5}$, fazem parte deste grupo, áreas com limitado desenvolvimento turístico, com modestas infraestruturas e fluxos turísticos. De acordo com MAE (2005) a costa do distrito abrange a Zona Turística de Sofala, que entre as várias praias que possui, destacam-se a praia da Beira, Sofala e Savane.

De acordo com os GTs do distrito, Dondo registrava considerável fluxo turístico 
Turismo de base local no distrito de Dondo (Moçambique): discutindo fatores de sustentabilidade

no período colonial, captando tanto fluxos locais, como da região. Maior parte do fluxo se dirigia para o litoral, o interno era constituído essencialmente por citadinos das cidades vizinhas e o externo por zimbabweanos, malaweanos, portugueses e norteamericanos. Normalmente, maior parte do fluxo dos turistas que passava pelo distrito, tinha como destino final o Parque Nacional de Gorongoza.

A guerra civil que o país viveu após a Independência (1975), levou ao colapso da atividade turística no distrito e no país em geral. Com o estabelecimento da paz em 1992, verificou-se uma reativação progressiva da atividade turística pelo país, o interesse do governo distrital pelo turismo é recente como foi referido anteriormente, pois o distrito já vem recebendo novamente os fluxos turísticos domésticos e internacionais e, assim o turismo foi se desenvolvendo espontaneamente.

O PEDTM recomenda para as APITs AB, além de somente beneficiar-se do turismo dos citadinos da região, a captação dos fluxos que se dirigem para os países vizinhos tendo como portal de entrada principal o aeroporto internacional da Beira. Fato que já tem se verificado, pois segundo os GTs, $90 \%$ dos turistas estrangeiros que chegam ao distrito vêm dos países vizinhos como África do Sul, Zimbabwe, Malawe e Tanzânia com destino final ao Parque Nacional de Gorongoza e Reserva Nacional de Marromeu.

Este plano recomenda ainda, a criação de infraestruturas como parques de campismo e caravanas para turistas de posses baixa, médias e alta, bem como, modernização e construção de novo parque hoteleiro.

O TBL focaliza-se no desenvolvimento com base nos recursos produtivos locais, promovendo a diversificação das atividades e, consequentemente, das fontes de rendimento das famílias, estimulando também, a valorização da cultura e no espaço rural. Está atividade por característica alicerça-se nas forças endógenas do local, uma vez que preconiza a utilização de recursos próprios do lugar, (CAVACO, 1996; CORIOLANO, 2003).

Nesta perspectiva, para a implantação do TBL no distrito de Dondo, há que considerar além dos recursos naturais e culturais, às infraestruturas básicas e turísticas existentes, uma vez que neste modelo agrega-se e não apropria-se de forma excludente do modo de vida que caracteriza o lugar. Como refere Rodrigues (2007, p.19) o turismo de base local deve considerar a escala local território - zona de resistência, os não alcançados pela globalização, compreendidos como "territórios de abrigo e recurso, prenhes de simbologia, onde predominam as relações de poder local, ancoradas nos princípios de liberdade e autonomia".

No que concerne à infraestrutura turística, os gestores do turismo afirmam que a rede de empreendimentos turísticos é estimada em 75 estabelecimentos, onde 43 se encontram encerrados em virtude de descapitalização dos operadores turísticos. Os 32 em funcionamento são constituídos por restaurantes, bares, lanchonetes, discotecas, pensões, hotéis, e lodges. $80 \%$ dos capitais investidos nos equipamentos turísticos do distrito são de origem estrangeira (paquistaneses, somalianos, zimbabweanos e portugueses), e semelhantemente acontece com o comércio formal. Maior parte dos locais que têm alguma atividade comercial integra-se no setor informal. 
Segundo os entrevistados (lideres comunitários-LCs e GTs), não existe ainda iniciativas significativas de turismo implementadas pela própria comunidade, o que mais tem se verificado, é o emprego dos locais nos empreendimentos turísticos como hotéis, lodges (Figuras 2 e 3), pensões, entre outros; fornecimento de produtos agrícolas, pesqueiros e artesanais; contratação de serviços de grupos de canto e dança, que são na maioria das vezes feitos pelos gestores dos lodges que encontram no litoral.

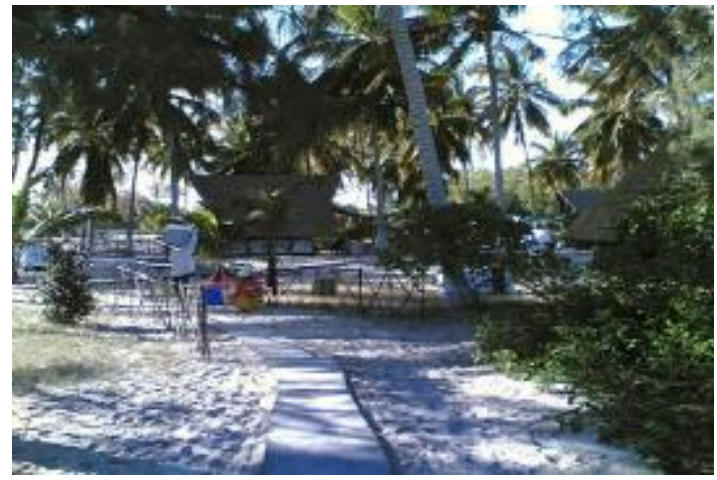

Figura 2: Lodge Rio Savane.Fonte: autores (2012). Figure 2: Lodge Rio Savane. Source: authors (2012).

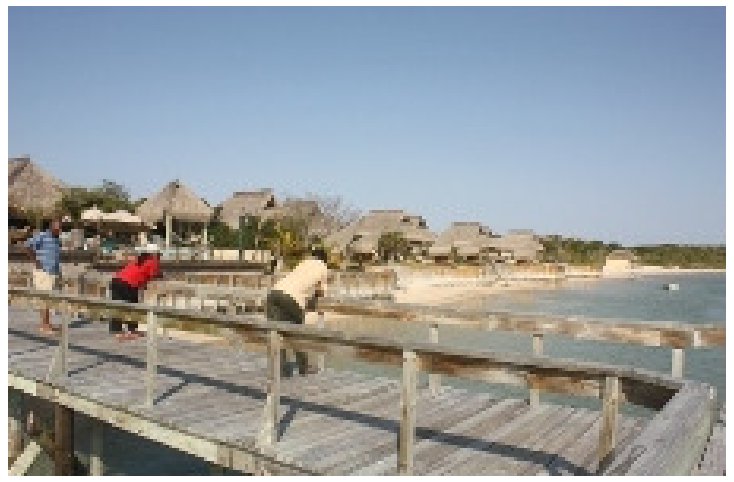

Figura 3: Savane Lodge. Fonte: autores (2012).

Figure 3: Savane Lodge. Source: authors (2012).

Os poucos serviços turísticos que são oferecidos pela comunidade distribuem-se entre alojamento em pensões (2), alimentação em lanchonetes (4), entretenimento em bares (2) e discoteca (1). Os que mais se destacam são as quintas (sítios), que para além de alojamento oferecem também serviços de alimentação e entretenimento.

Existem no distrito, pelo menos 33 quintas, somente 3 é que se dedicam ao turismo. 1 se localiza no posto administrativo de Mafambisse (Figura 4) e 2 no posto administrativo de Savane (Figura 5), convém ressaltar que as quintas pertencem a membros da comunidade com posses média a alta, que agregaram o turismo as quintas estimulados pelo fluxo de citadinos da Beira e Chimoio, que se dirigiam a Dondo para lazer, nos finais de semana e feriados. Cabe ressaltar, que os proprietários das quintas exploram a atividade individualmente e, a de Mafambisse o proprietário é da cidade da Beira e esta foi a primeira a abrir suas portas para o turismo em 1996.

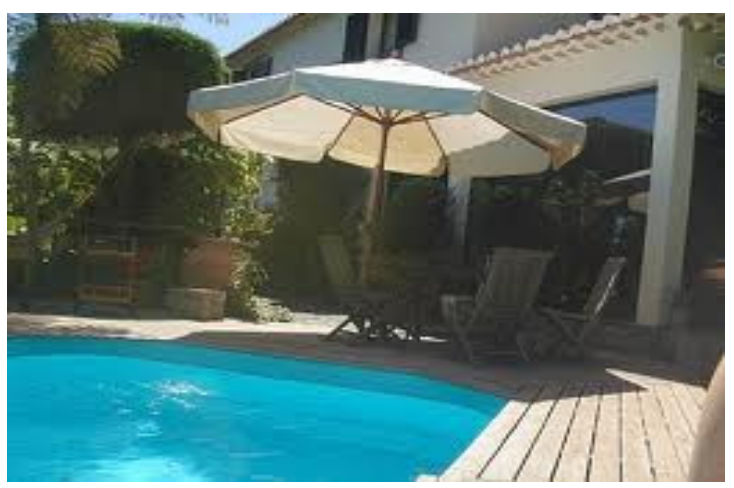

Figura 4: Quinta de Mafambisse. Fonte: autores (2012). Figure 4: Quinta de Mafambisse. Source: authors (2012).

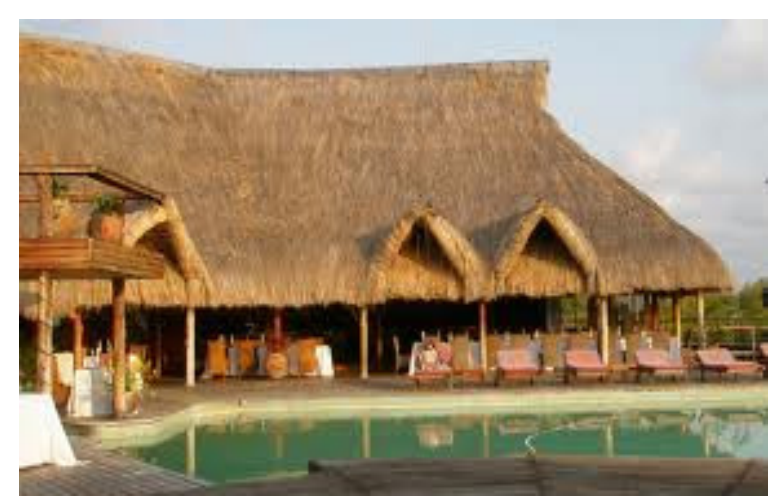

Figura 5: Quinta de Savane. Fonte: autores (2012). Figure 5: Quinta de Savane. Source: authors (2012). 
As quintas, para além de alojamento e alimentação, oferecem também passeios em barcos tradicionais pelo rio Savane e Maria e pela praia de Savane (Figuras 6 e 7), pesca e caça. O serviço de alimentação é constituído tanto por pratos típicos da região como por pratos convencionais.
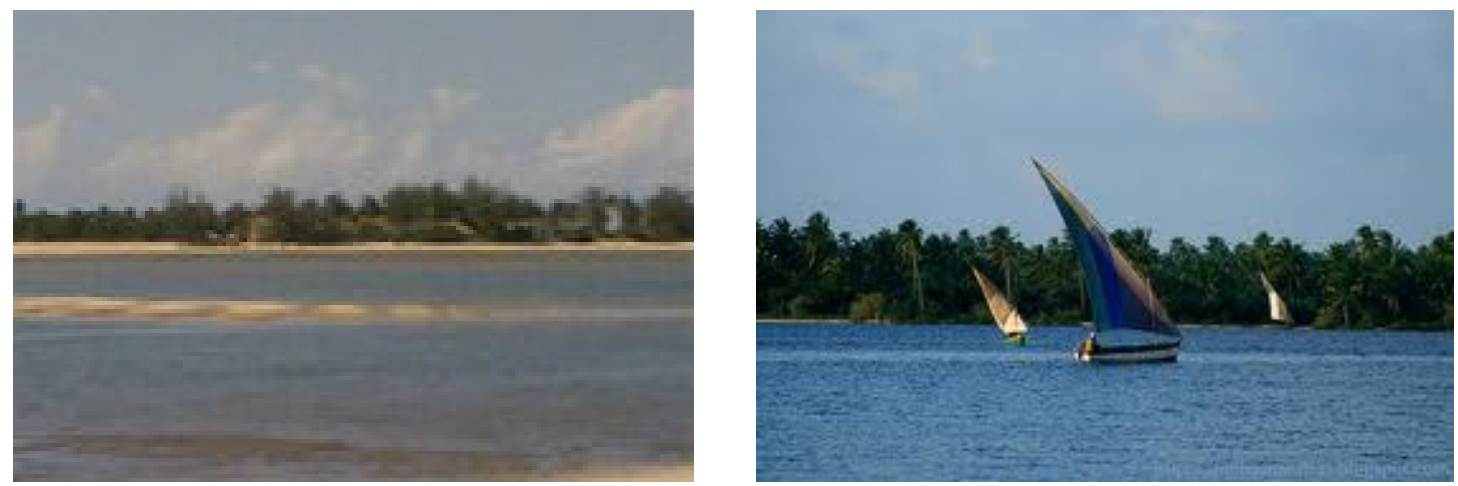

Figuras 6 e 7: Rio Savane. Fonte: autores (2012).

Figures 6 and 7: River Savane. Source: authors (2012).

Tem se verificado também, a realização de feiras gastronômicas (esporadicamente), de produtos agropecuários e pesqueiros e, de artesanato. A feira que tem tido maior afluência é a de produtos agropecuários e pesqueiros, observando-se a presença de comerciantes das cidades da Beira, Chimoio e Maputo.

Apesar de se verificar um crescente interesse pelo turismo por parte do governo local, ainda prevalece à ideia de que o distrito de Dondo é potencialmente pobre em recursos turísticos, como se pode constatar pela afirmação dada por um dos GTs

\begin{abstract}
O distrito não tem grande vocação turística para apostarmos em grandes esforços de investimentos no turismo. O que chama atenção quando se trata de turismo aqui no distrito é a praia de Savane e a praia de Sengo, mesmo na praia de Sengo não existe nenhuma infraestrutura, foi tudo destruído pela guerra, para se chegar lá é difícil. Mas o governo está trabalhar junto de potenciais investidores e da comunidade nos arredores da praia de Sengo para a reativação do complexo turístico que existia no tempo colonial.
\end{abstract}

Esta ideia também está presente no perfil do distrito, "Este distrito não tem potencial turístico significativo e as infraestruturas necessárias ao desenvolvimento do sector são muito limitadas" (MAE, 2005, p.3). Os resultados da pesquisa, indicam que esta ideia, está relacionada à ligação do turismo a viajem, sol e praia, pois $90 \%$ dos entrevistados quando questionados sobre as ideias que lhes ocorrem quando se fala de turismo, são viajar e praia.

Além disso, resulta também do atual foco de desenvolvimento de turismo que o governo tem direcionado para o país, que é o turismo de massa (turismo de sol e praia), uma tipologia de turismo "altamente destrutiva", pois, pela forma como este se desenvolve acelera a degradação dos destinos tanto nos aspectos naturais como culturais, além de aumentar a desigualdade social.

Perante problemas dessa natureza, Castells (2001) afirma que o Estado é chama- 
do a intervir por meio de incentivos, subsídios, atividades complementares que estimulem a participação dos agentes de desenvolvimento, assim como ações de formação e conscientização das comunidades em relação aos prós e contras do turismo.

Portanto, percebe-se que maior parte dos problemas vividos pelas comunidades como a falência dos seus estabelecimentos, a falta de conhecimento sobre o turismo, carência dos meios básicos para oferecer o produto turístico, podem encontrar solução, ou pelo menos caminho para solução mediante maior comprometimento do poder público através do sugerido por Castells (2001) no inicio deste paragráfo.

De fato, o distrito Dondo carece de infraestruturas, tanto básicas como turísticas que permitam o pleno desenvolvimento da atividade, como se mostra na secção do texto onde estão descritas as características socioeconômicas do distrito. Mas, afirmar literalmente que o distrito não tem potencial turístico significativo é negar-se o olhar as outras oportunidades para o aproveitamento dos recursos disponíveis no distrito, e que podem trazer benefícios reais as comunidades locais sem descaracterizar a paisagem, degradar a natureza ou mercantilizar a cultura.

É de notar, que em virtude do interesse do governo local e de agentes econômicos externos pelo turismo no distrito de Dondo, a Assembleia Municipal de Dondo aprovou a proposta de o Município retirar todas as quintas existentes na zona de expansão para as zonas de produção. Conforme os LCs, as zonas de expansão são destinadas a construção de unidades residenciais, maior parte de indivíduos proprietários de quintas nesta zona, são indivíduos que tem as suas quintas como moradia familiar ou lugar para lazer e não unidade de produção.

Os ambientalistas que atuam em Dondo informaram que o fato de as zonas de produção albergar a estrutura industrial do distrito (Fábrica de cimentos, de lusalite, de betão, processamento de madeira), deixará os proprietários das quintas transferidos para está zona, expostos as várias formas de poluição (sonora, do ar, água, etc.) e possibilidade de contração de doenças cancerígenas em longo prazo. Porém, o projeto para reativação do complexo turístico de Sengo, bem como, o plano para concessão dos terrenos na zona de expansão para atividade turística mostra-se ainda continuam em curso.

Além do alerta pela transferência das quintas para a zona de produção, consta no Jornal Notícias do dia 22 de Outubro de 2011, outro alerta sobre a intenção de estimular o turismo de massa na praia de Sengo (Figuras 8 e 9), uma vez, atualmente tem se registrado um desmatamento massivo do mangal e com a implantação do turismo será prejudicial para a vida marinha.

Porém, os gestores de turismo no distrito não tomaram em consideração o alerta dado pelas associações ambientalistas, tanto que, voltaram a afirmar no Jornal Notícias do dia 28 de Dezembro de 2011, que o principal interesse no momento é de reativar o turismo em Sengo como se observa na afirmação abaixo:

Para já, a maior preocupação do Governo reside na reativação do turismo nas praias de Sengo, cuja via condiciona o seu acesso. Com infraestruturas completamente em escombros, incluindo o desaparecimento do mapa da então pista de aterragem devido à guerra, a referida zona turística apresenta-se com uma beleza natural altamente atraente com a abundância de ecossistemas marinhos, faunísticos e florestais (JORNAL NOTÍCIAS, 2011). 
Turismo de base local no distrito de Dondo (Moçambique): discutindo fatores de sustentabilidade
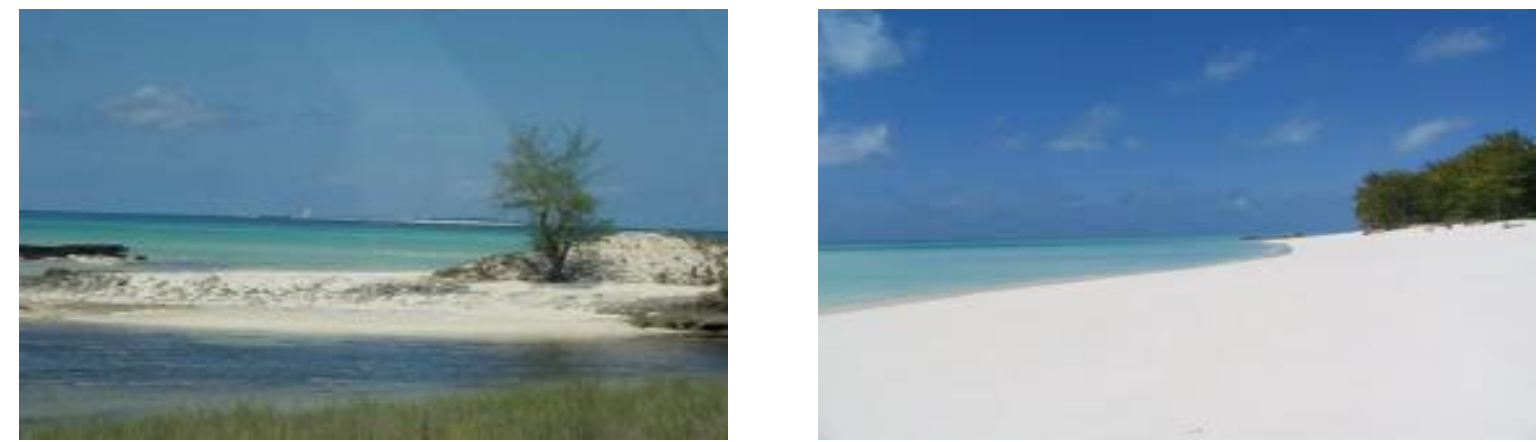

Figuras 8 e 9: Praia de Sengo. Fonte: autores (2012).

Figures 8 and 9: Beach Sengo. Source: authors (2012).

Esta atitude dos gestores da atividade turística no distrito só vem confirmar, que a lógica economicista impera no mercado e no seio dos agentes de turismo no distrito. Todavia, vários pesquisadores entre eles Coriolano (2005), e Burzstyn (2004) defendem que uma das vias para ultrapassar as vicissitudes criadas pelo turismo de massa é a implementação do turismo de base local, que se traduz em uma prática turística que promove a inclusão social por meio de implantação ou incentivo à criação de empreendimentos locais e com uma visão própria de exploração consciente e sustentável voltada aos interesses na escala humana e local.

Todavia, as dificuldades se agravam em regiões com considerável fragilidade do poder político local, desigualdade social e baixo grau de organização social, para além da grande prevalência do turismo de massa no seio dos profissionais, políticos, maioria dos turistas e até das comunidades receptoras (BURZSTYN, 2004).

E este é cenário que está se impondo no distrito de Dondo, pois, tanto os gestores públicos como as comunidades locais vêm o turismo de massa como um meio de "propulsão veloz" para a melhoria da qualidade de vida, como se pode perceber na afirmação dos líderes comunitários "se o complexo de Sengo estivesse aberto o negócio das pessoas aqui teria mais lucro, porque aproveitariam os turistas que viriam para cá.

Percebe-se que por a atividade turística ter iniciado espontaneamente no distrito, sem obedecer a nenhum plano, fez com que os empreendimentos surgissem nos lugares que se mostram atrativos aos investidores, com destaque para o litoral e a zonas próximas a EN1. Mas a riqueza do distrito vai além de praias, o distrito tem uma beleza natural atraente com abundancia de ecossistemas marinhos, faunísticos e florestais, o pescado e mariscos constituem alguns dos produtos que fazem parte da dieta da comunidade, pois o distrito é rico em cursos de água (rios, riachos, lagoas). A caça também é uma das atividades muito praticada pelos locais, e também oferecida pelos operadores turísticos existentes.

Os Serviços de Atividades Econômicas no distrito em colaboração com a Direção Provincial para Coordenação da Ação Ambiental da Província de Sofala e ONGs que trabalham em questões ambientais em Dondo têm realizado programas de educação ambiental no distrito, de acordo com os LCs as comunidades têm consciência da necessidade de conservação do meio ambiente. Foram capacitados 4 grupos de ativistas, compostos por 15 membros da própria comunidade e existem 3 associações comunitárias direcionadas para o meio ambiente e desenvolvimento. 


\section{Sustentabilidade social}

De acordo com o art. 3 da Constituição da República, Moçambique é um estado de direito baseado no pluralismo de expressão, na organização política democrática, no respeito e garantia dos direitos e liberdades fundamentais do homem. Um dos objetivos do estado moçambicano é o reforço da democracia, da liberdade, da estabilidade social e da harmonia social e individual (art. 11, al. f da Constituição da República de Moçambique). Para efetivação destes objetivos, o Estado atua por meio dos seus órgãos centrais e locais, no entanto, são os órgão locais responsáveis pela implementação de processos de desenvolvimento que levem a melhoria da qualidade de vida da comunidade.

Assim, os órgãos locais onde se integra o governo distrital possuem autonomia administrativa na gestão dos recursos locais, os mesmos são responsáveis pela promoção a utilização de recursos disponíveis, garantia da participação ativa dos cidadãos e incentivo às iniciativas locais na solução de problemas da comunidade, para além de garantir a realização das tarefas e programas econômicos, culturais e sociais de interesse local e nacional (arts. 263 № 2 e 264 da Constituição da República de Moçambique, ATLs).

Deste modo, o processo de desenvolvimento adotado passa por uma abordagem territorial onde o processo de gestão e planejamento é policêntrico com múltiplas instâncias de discussão e decisão, haja vista que cada distrito é responsável pela criação de sua própria riqueza com base nas especificidades locais e/ou regionais.

Apesar de ter se verificado vários investimentos em infraestruturas como melhoramento das vias de acesso (primárias e secundárias), rede de comunicação e de distribuição de água, a qualidade de vida da população local ainda está aquém do nível desejado. Somente $19,5 \%$ da população do distrito é que se beneficia de água canalizada, abrangendo apenas a cidade de Dondo e os postos administrativos. A distribuição de energia elétrica também é precária, cobrindo somente $13 \%$ dos agregados familiares do distrito e, $78 \%$ das famílias utilizam combustíveis como parafina, petróleo ou querosene (INE, 2008).

A taxa de escolarização foi estimada em $72,4 \%$ respectivamente considerando-se apenas o ensino primário e secundário e, a taxa de analfabetismo em nível do distrito é de $35 \%$, o que demonstra que menos da metade da população não sabem ler nem escrever em nenhuma língua (INE, 2008).

Tendo em conta que a língua materna dominante no distrito é Sena, 65\% da população com mais de 5 anos de idade ou mais tem conhecimento da língua portuguesa, sendo este predominantemente em homens dada a maior inserção na vida escolar e no mercado de trabalho. Cabe ressaltar que maior parte da população alfabetizada vive na cidade de Dondo.

Os serviços sanitários também não respondem a demanda real do distrita, quando se trata de problemas de saúde grave ou procura de serviços que não são oferecidos nos centros de saúde, a população tem de se deslocar a cidade da Beira $(30 \mathrm{~km})$ para o atendimento em serviços de saúde.

No que respeita a posse da terra, mais de $85 \%$ das 59000 parcelas em que estão divididas, as explorações são tradicionalmente pertença das famílias da região, sendo transmitidas por herança aos filhos, ou estão em regime de aluguer ou concessão do es- 
tado a particulares e empresas privadas.

Este distrito possui potencialidades agrícolas, pecuárias e florestais, sendo a agricultura e pecuária as principais atividades das famílias. De um modo geral a agricultura é praticada manualmente em pequenas explorações familiares em regime de consorciação de culturas com base nas variedades locais.

O distrito possui cerca de 26 mil explorações agrícolas com uma área média de 0.8 hectares. É de notar que o tipo de exploração dominante é a familiar. Na sua maioria os terrenos não estão titulados e, quando explorados em regime familiar, têm como responsável, em quase $80 \%$ dos casos o homem da família.

Dada a composição alargada da maioria dos agregados moçambicanos, a estrutura de exploração agrícola do distrito reflete a base da economia familiar, constatando-se que as explorações são cultivadas por 6 ou mais membros do agregado familiar. As explorações estão divididas em cerca de 59000 hectares e exploradas em 55\% dos casos por mulheres. Do total de agricultores, 34\% são crianças menores de 10 anos de idades, de ambos os sexos.

A produção agrícola é feita normalmente em condições de sequeiro, no entanto, este método apresenta um risco alto de perdas de colheitas, devido à baixa capacidade de armazenamento de umidade no solo durante o período de crescimento das culturas. Para além da agricultura, a população local dedica-se a caça, pesca, extração de carvão, artesanato.

O distrito de Dondo é um centro agroindustrial importante do país, sendo a produção de açúcar e cimento que dominam a atividade industrial do distrito. Há ainda a realçar entre outros empreendimentos a Lusalite de Moçambique, Moçambique Florestal (MOFLOR), Fábrica de Travessas de Betão, Estação dos Caminhos de Ferro Moçambique-Centro e Gado Leiteiro de Muzimbite. O distrito possui uma boa integração a rede de mercados devido a proximidade da cidade da Beira, a integração no Corredor da Beira e o acesso fácil à província vizinha de Manica e mesmo ao Zimbabwe.

É de notar que verifica-se uma considerável participação da comunidade no processo de gestão no distrito, pois a autoridade comunitária tem contribuído largamente na implementação de vários programas do Governo nomeadamente:

- Incremento de receitas do estado através de cobrança de imposto; Redução dos casos criminais, resultantes de problemas sociais e de conflitos de terras (polícia comunitária);

- Apoio às instituições do estado, na gestão do programas de combate ás queimadas descontroladas e fomento pecuário;

- Sensibilização e mobilização das comunidades para o sucesso dos programas de vacinação, inquéritos, combate ao HIV/SIDA, expansão da rede escolar, promoção do gênero (rapariga), diminuição do índice de desistência nas escolas, reabertura de vias terciárias, construção de salas de aulas e casas de professores e presidentes das localidades nas zonas rurais, entre outras;

- Dependendo de sua participação, as autoridades comunitárias recebem como estímulos 300,00Mts por cada participação na gestão da terra e 5\% do valor do imposto arrecadado. 
Embora se afirme acima, a existência de participação da comunidade, questiona-se a qualidade dessa participação, uma vez que percebe-se ao longo deste discurso que as comunidades estão desprovidas de conhecimento sobre a atividade turística nesse caso, a ponto de poderem dar algum parecer sobre investimentos em turismo. Empoderamento não significa somente atribuir cargo de poder a um membro da comunidade, conforme Carestiano (2000) o empoderamento das comunidades possibilita a participação plena dos mesmo nos processos decisórios e de gestão dos recursos locais.

Em (GREEN, 2009) consta que cidadãos ativos são aqueles que têm pleno gozo dos seus direitos e obrigações e exercitam-nos com vista a obter melhor qualidade de vida, participando da vida política ou cívica ou ainda através de ações coletivas que possibilitam a camada excluída da sociedade sejam ouvidas. Estados efetivos, àqueles que são capazes de garantir aos indivíduos, o poder sobre os seus direitos e obrigações conferindo-Ihes a possibilidade de exercer a cidadania.

Assim, a ação dos indivíduos está sujeita não somente a atribuição desse poder (cargo de chefia, por exemplo líder comunitário), agrega-se o senso do poder da informação/conhecimento por parte da comunidade, bem como a abertura por parte do estado a ouvir e dar cobro as preocupações das comunidades bem como as restantes partes interessadas no desenvolvimento do distrito, a baixa atenção por parte do poder público no distrito ao alerta feito pelas organizações em prol do ambiente para o turismo de massa que se projeta para a llha de Sengo, é um indício da não efetividade do poder público no distrito.

As condições de vida e de habitações também deixam muito a desejar, as mais observadas no distrito de Dondo, são do tipo palhota com pavimento de terra batida $(61,5)$, teto de capim ou colmo $(15,5)$ e paredes de caniço ou paus $(55,3 \%)$. Em relação a outras utilidades, o padrão dominante é o de famílias sem rádio, sem eletricidade e com água colhida diretamente em poços ou furos, vivendo em palhotas sem latrina dispondo em média de duas bicicletas.

A cidade do Dondo e a vila de Mafambisse são as zonas que apresentam melhores condições habitacionais, verificando-se que maior parte das famílias tem rádio e vivem em casas com latrina, cerca de $15,6 \%$ têm casas de material duradouro, energia elétrica e água canalizada.

Conforme pode se constar, a situação social do distrito pode se considerar como baixa, há uma necessidade de investimento em infraestruturas coletivas que proporcionem a população melhores possibilidades de aproveitamento dos recursos produtivos, por exemplo, a falta de energia elétrica tem sido um dos grandes constrangimentos para os pescadores que não tem como congelar o seu pescado, sendo obrigados a vender e consumir tudo no mesmo dia e, em caso de sobra vai para o lixo (LCs). Todavia, ainda pode se colocar em perspectiva a implementação do TBL como forma de criar outras formas de aproveitamento de dos recursos, de modo a complementar as já existentes.

As palhotas constituem o modelo tradicional de casas do espaço rural Moçambicano, o que se propõem é disponibilização de recursos para as comunidades para que elas possam construir palhotas que ofereçam melhores condições para moradia e para acomodação de turistas, pois o turismo de base local, não vem para alterar a forma local, mas sim para nela se integrar. 


\section{Sustentabilidade cultural}

Nesta seção foram observados aspectos como participação comunitária, autenticidade, consciência social e pública sobre identidade local, inserção local e regional e, experiência turística.

$90 \%$ dos entrevistados não têm conhecimento que lhes possibilite um julgamento fiável quando se trata de turismo. Quando questionados sobre a idéia ou noção que possuem do turismo, maior parte referiu-se a viagem e praia; como vantagens do turismo a oportunidade de emprego e mercado para produção local, como desvantagens somente o reassentamento necessário para implantar o turismo para um "beneficio maior". Portanto, percebe-se que a comunidade local não tem consciência do que é turismo e as diferentes perspectivas do mesmo. Só para constar, no seio dos gestores de turismo não existe nenhum com formação em turismo, o que fragiliza ainda mais o processo de gestão do turismo no distrito.

De certa forma, a comunidade não é culpada por abrir as portas para o turismo de massa, uma vez que eles não conhecem as várias perspectivas do turismo, isto é, não entendem realmente o que é o turismo, os reais benefícios e desvantagens do turismo, nem sabem como efetivamente se manifesta o turismo de massa, não conhecem outras formas de turismo para que possam escolher o melhor para elas.

Durante a auscultação para a reativação do complexo turístico de Sengo, o que Ihes foi informado apenas é que com o investimento em turismo no distrito elas poderão ter emprego, terão mais mercado para vender o seu peixe, carvão, a produção agropecuária, artesanato, pois o distrito estará cheio de turistas (LCs).

Para a implantação da atividade turística seja qual for à modalidade, é necessário que o local esteja minimamente preparado em todas as dimensões, de contrário o turismo poderá trazer mais os seus efeitos negativos do que os positivos.

De acordo com os entrevistados, não existe nenhum programa de conscientização em relação ao turismo, as atividades de formação ou capacitação que a comunidade tem recebido estão relacionadas à atividade agropecuária e pesca, tem se realizado também programas de educação ambiental implementadas pelo departamento de Coordenação para Ação Ambiental e por ONGs que atuam no distrito em questões ambientais.

Além disso, não existe nenhum plano específico ao desenvolvimento do turismo ou pelo menos uma projeção do tipo turismo que se quer trazer para o distrito. Devido ao interesse de investidores externos pelo turismo no distrito e, mediante as vantagens econômicas que o governo local espera ter, iniciaram-se ações para implementação do turismo no distrito.

Uma das primeiras ações foi uma reunião conjunta com a comunidade onde se explanou sobre as intenções de estimular o turismo no distrito com ênfase no turismo de massa, e não no turismo que pode ser implementado pela própria comunidade, como referem os líderes comunitários: 
O governo e os investidores reuniram conosco, nos falaram do turismo e da reabilitação do complexo de Sengo, disseram que o turismo nas praias vai criar empregos, que vamos poder vender nossos produtos, que as infraestruturas assim como outros serviços vão melhorar, os investidores vão construir postos de saúde e escolas, por isso achamos que o turismo é bom e vai nos ajudar muito, por isso concordamos (LCs)

Como se pode ver, os primeiros passos do governo para a implantação do turismo no distrito estão direcionados para um turismo "predador", onde a comunidade não tem participação ativa e nem preparação para receber o turismo, em curto prazo degradará com os valores locais, com modo de vida local, com o ambiente e a cultura. Apesar de as decisões serem tomadas em conselhos ou reuniões com a comunidade ou seus representantes, a participação pelo menos em turismo é limitada porque as pessoas não têm consciência do que é realmente o turismo e como elas podem participar.

O caminho iniciado pelo governo local pode levar a mudança do modo de vida local, por exemplo, as atividades rotineiras da comunidade serão substituídas por postos de trabalhos nos hotéis e lodges no litoral do distrito, já há intenção de retirar as quintas do lugar em que se encontram para dar espaço ao turismo. Há que convir, que todas estas ações são desnecessárias, pois há modelos alternativos de turismo cujas vantagens são maiores que as desvantagens, onde a comunidade local é a protagonista no desenvolvimento da atividade como foi referido anteriormente.

Vários autores como Kageyama (2004), Candiotto (2010), Campanhola e Graziano da Silva $(1999,2000)$ identificam o turismo como uma atividade potencial para o melhor aproveitamento dos recursos naturais, assim como culturais. E de forma o especifica, o turismo de base local se mostra propício para um desenvolvimento que se quer sustentável, inclusivo socialmente onde a participação constitui o forte para o engajamento da comunidade no aproveitamento dos recursos locais. Conforme Carvalho (2007), este modelo se foca em um turismo e o tipo de turista, que procura uma experiência cultural original, o contato com o novo, como também localidades receptoras onde os habitantes adotam uma postura alicerçada na sustentabilidade na prática das atividades turísticas, preservando a cultura e as estruturas sociais do lugar, de modo que os parâmetros da cidadania se interagem com o desenvolvimento do turismo local.

Face ao exposto, constata-se que o distrito goza de uma boa inserção a nível do mercado regional, a comunidade vive segundo seus hábitos e costumes, verifica-se a afirmação da identidade local no seio da comunidade, o nível de participação da comunidade na vida pública e na gestão dos recursos é significativa, pois existem mais de 15 associações no distrito distribuídos entre as áreas de saúde, educação, gênero, ambiente, agricultura, pesca, artesanato, cultura, pecuária, atividade industrial, educação cívica e responsabilidade social.

No entanto, compreende-se que não há nenhuma cooperação ou uma forma de associativismo em turismo pela falta de consciência da comunidade em relação ao fenômeno, além disso, o turismo ainda está numa fase embrionária. Todavia, os resultados da pesquisa mostram que há condições para se colocar em perspectiva a implementação do TBL.

É importante destacar que o TBL possibilita a inclusão social uma vez que as co- 
Turismo de base local no distrito de Dondo (Moçambique): discutindo fatores de sustentabilidade

munidades podem atuar em parceria e cooperação, buscando conjuntamente soluções para os problemas do grupo. E isso, só é possível mediante a criação de um ambiente interativo e de parceria entre os empresários do setor de turismo e o poder público, que deve se preocupar com a melhoria da qualidade de vida e com o bem estar social da comunidade.

Assim, pode se afirmar que o distrito reúne condições para implementação do TBL, desde que haja um trabalho sobre conscientização e capacitação da comunidade, governos local em matérias ligadas ao turismo e técnicas de gestão para uma melhor participação da comunidade no desenvolvimento do turismo no distrito.

\section{Sustentabilidade econômica}

Além dos fatos acima expostos, o distrito possui o Fundo de Desenvolvimento do Distrito (FDD) orçados em 9 milhões de Meticais, cuja finalidade é disponibilizar capitais a comunidade para poderem investir em atividades produtivas que levem a melhoria de sua qualidade de vida. O Instituto Nacional de Turismo (INATUR) também dispõe de fundos para investimentos em turismo, mediante apresentação de um projeto que se mostre viável economicamente, socialmente e ambientalmente. Mas como a visão da comunidade local limita-se apenas nas atividades tradicionais e o turismo é tido somente como uma atividade muito cara para se investir, os fundos da INATUR nunca foram solicitados por nenhum membro da comunidade e até ao momento atual o FDD só foi solicitado para investimento na agropecuária, pesca, artesanato, comércio e atividades afins desenvolvidas pela comunidade.

Schaerer e Dirven (2001) apontam como constrangimentos que levam os empreendimentos locais a falência ou as comunidades não enveredem pelo turismo como uma opção para melhoria da sua qualidade, alguns optando até, por vender suas propriedades a empresários urbanos com maior poder de capital, são a dificuldade de investimento inicial, a baixa qualificação, resistência a iniciativa por parte dos locais são citadas como Perante problemas dessa natureza. Entretanto, Perante problemas dessa natureza, Castells (2001) afirma que o Estado é chamado a intervir por meio de incentivos, subsídios, atividades complementares que estimulem a participação dos agentes de desenvolvimento, assim como ações de formação e conscientização das comunidades em relação aos prós e contras do turismo.

Nesse caso, em vez de somente atrair investimentos externos para o distrito, devese também buscar apoio para as comunidades, de modo que elas estejam aptas para implementar o TBL. Ademais, o distrito vem registrando um fluxo crescente de turistas e, por se encontrar no corredor recebe também camioneiros ${ }^{6}$, o turistas tem uma permanência média de 3 dias. As épocas altas de turismo doméstico são os feriados e finais de semana para o turismo internacional é de Outubro a Janeiro.

Os resultados da pesquisa sugerem que o TBL se mostra como uma alternativa exequível no distrito de Dondo, pois, além dos atributos naturais e culturais e, aliados a acessibilidade que se constitui num fator diferencial no distrito, existe uma boa rede de cooperação no distrito, embora não seja na área de turismo. É de notar que um dos fatores primordiais para esta modalidade é a cooperação, solidariedade e o espírito de pertencimento ao lugar. 
Nesse sentido, cabe ao governo local a elaboração e implementação de políticas públicas e estratégias que considerem as especificidades e a complexidade territorial no seu todo, e busca por caminhos que proporcionem benefícios efetivos a comunidade local, não simplesmente se direcionando pelas vantagens econômicas. Além disso, o TBL mostra-se como uma possibilidade para as comunidades inovarem e diversificarem as suas atividades sem necessariamente terem de trocá-las pelo turismo.

\section{Conclusão}

Esta análise aponta que teoricamente o turismo de base local se apresenta como uma alternativa para melhoria da qualidade de vida da população rural, pois em vez de substituir as atividades já praticadas pelas famílias, este as complementa. Este modelo baseia-se no aproveitamento dos recursos turísticos alicerçados nos princípios de sustentabilidade, valorizando a cultura e o modo de vida rural. Em suma, pode se dizer que o distrito de Dondo apresenta forte potencial turístico reunindo condições para a implementação do TBL, mas para isso faz-se necessário que se cumpra primeiramente os seguintes requisitos:

- Educação da comunidade em relação ao turismo em suas diversas perspectivas;

- Conscientização frequente sobre o valor e a preservação da identidade local;

- Mudança de foco dos instrumentos de gestão de turismo, de turismo de massa para modelos alternativos que se enfocam no bem estar da comunidade;

- Elaboração de políticas e planos em nível local que espelham de modo específico o perfil turístico do distrito e como serão aproveitados os recursos turísticos do distrito;

- Criação de redes de relações sociais orientadas para o turismo, de modo que a comunidade tenha capital social disponível que lhes permita implementar o TBL;

- Estimular a comunidade a solicitar os fundos disponíveis no distrito para investimentos no TBL;

- Cabe sugerir também, a implementação de um projeto piloto para implementação do TBL, de modo que os resultados do projeto se convertam em estimulo para implementação de iniciativas de gênero por várias regiões no interior do país.

Em síntese, pode se afirmar que o distrito de Dondo apresenta um potencial para implementação de um modelo de desenvolvimento de turismo de base local, pois ele é rico em recursos naturais e culturais, beneficia-se de uma boa rede de acessibilidade no contexto do mercado da região, a população vive segundo os seus hábitos e costumes e valorizam a sua identidade. Contata-se também uma boa cooperação entre os membros da comunidade, embora não seja em turismo, fato que se observa através do nível de participação da comunidade em associações, cooperativas, núcleos atuando em áreas como agricultura, pesca, extração de carvão vegetal, ambiente, educação cívica etc. Possui também fontes de financiamento públicas para incrementar ou estimular o investimento local. 


\section{Referências bibliográficas}

AZEVEDO, F.F. Desenvolvimento Local e Capital Social uma Abordagem Teórica. Geornordeste, São Cristovão-SE, ano XIX, n. 1, 2008.

BURNS, E.McN. História da Civilização Ocidental. 36 ed. São Paulo: Globo, 1995.

BURSZTYN, I. et al. Programa de Promoção do Turismo Inclusivo na Ilha Grande, RJ. Anais do Encontro nacional do turismo com base local. Paraná: Curitiba, 2004

CANDIOTTO, L.Z.P. Elementos para o Debate acerca do Conceito do Turismo Rural. Turismo em Análise. v 21, n. 1, 2010, p. 3-24. <http://www.search-docs.com/ agroturismo.html> Acesso em 17 Set. 2010.

CASTELLS, G. Turismo Atividade Marcante. 4. ed. Caixias do Sul: EDUCS, 2001.

CAVACO, C. Turismo rural e desenvolvimento local. In: RODRIGUES, A. B. (org.) Turismo e Geografia: reflexões teóricas e enfoques regionais. São Paulo: Hucitec, 1996. p. 94-121.

CHICHAVA, J.A.C. Participação comunitária e Desenvolvimento: o caso dos grupos dinamizadores em Moçambique. Maputo:ML Graphics. Maputo, 1999.

CORIOLANO, L.N.M.A Exclusão e a Inclusão Social e o Turismo. Revista de Turismo y Patrimônio Cultural. v. 3, n. 2, 2005.

CORIOLANO, L.N.M.; LIMA, LC. Turismo Comunitário e Responsabilidades Socioambiental. 1 ed. Ceará: EDUECE, 2003.

FALCÃO, M.C.; SANTOS, C.F.S.O; GOMEZ, C.R.P. Arranjos e Sistemas Inovativos Produtivos Locais: inovação e desenvolvimento para destinos turísticos - o caso de Porto de Galinhas. Pasos, v. 7, n. 3, 2009,p. 433-450. Disponível em: <http:// www.pasosonline.org>. Acesso em; 23 Jan 2011.

GRAZIANO DA SILVA, J. et al. O emprego rural e a "comoditização" do espaço agrário. São Paulo em Perspectiva, São Paulo, v. 11, n. 2, 1997.

GREEN, D. Da Pobreza ao Poder: como cidadãos ativos e Estados efetivos podem mudar o mundo. São Paulo: Cortez; Oxfam Internacional, 2009.

INSTITUTO NACIONAL DE ESTATÍSTICA (Moçambique). Estatísticas do Distrito de Dondo. 2008.

LOCATEL, C.D.; HESPANHOL, Antonio Nivaldo. As Políticas Públicas e as Mudanças de Concepção de Desenvolvimento Rural na Europa e no Brazil. Dinsponível em: <http://w3.ufsm.br/engrup/iiengrup/pdf/t31.pdf>. Acesso em: 10 Nov. 2011

MAX-NIFF, M.A. Desarrollo a Escala Humana: conceptos, aplicaciones y algunas reflexiones. Uruguai: Editorial Nordan Comunidad, 1998

Ministério de Administração Estatal. Perfil do Distrito de Dondo Província de Sofala. Maputo, 2005.

MOÇAMBIQUE. Plano de Ação para Redução da Pobreza Absoluta 2006-2009. Maputo, 2006. 
MOÇAMBIQUE. Política de Turismo e Estratégia de Sua Implementação. Maputo, 2003.

MOÇAMBIQUE. Lei n8/2003 lei dos Orgão Locais do Estado. Maputo, 2003

MOÇAMBIQUE. Plano Estratégico para o Desenvolvimento do Turismo em Moçambique 2004 - 2013. Maputo: 2004

MOÇAMBIQUE. Estratégia de Desenvolvimento Rural. Maputo, 2007

PUTNAM, R,D. Comunidade e democracia: a experiência da Itália moderna. 3. ed. Rio de Janeiro: Editora FGV, 2002.

RIVEROS, H.; BLANCO, M. El Agroturismo, Uma alternativa para Revalorizar La Agroindústria Rural como Mecanismo de Desarrolo Local. Lima: PRODAR, 2003. Disponível em; <http://www.search-docs.com/agroturismo.html> Acesso em 17 Set. 2010

RODRIGUES, A.B. Turismo e Desenvolvimento Local. São Paulo: Hucitec, 1997

SCHAERER, J.; DIRVEN, M. EI turismo Rurale em Chile: experiência de agroturismo em las regiones de EI Maule, La Araucanía e los Lagos. Santiago do Chile: Nações Unidas, 2001. Disponível em: <http://www.search-docs.com/agroturismo.html>. Acesso em 17 Set. 2010

SEN, A. Desenvolvimento como Liberdade. São Paulo: Companhia das Letras, 2000.

VERBOLE, A. A. Busca pelo Imaginário Rural. In: RIEDL, M.; ALMEIDA, J.A.; VIANA, A.L.B. (Org.). Turismo Rural: tendências e Sustentabilidade. Santa Cruz: EDUNISC, P. 117-140, 2002.

\section{Notas:}

${ }^{1} \mathrm{O}$ distrito de Dondo localiza-se a $143 \mathrm{~km}$ da cidade de Chimoio a capital da província de Manica, a província vizinha citada.

${ }^{2} \mathrm{O}$ termo alternativo refere-se às práticas ou modalidades de turismo opostas ao tradicional turismo de massa.

${ }^{3}$ Entende-se por articulação orgânica, as relações que se estabelecem entre os seres humanos com a natureza, as tecnologias globais com as locais, o individuo com o social, a planificação baseada na autonomia da sociedade civil com o Estado.

${ }^{4} \mathrm{O}$ distrito de Dondo localiza-se a $143 \mathrm{~km}$ da cidade de Chimoio a capital da província de Manica, a província vizinha citada, $30 \mathrm{~km}$ da cidade da Beira.

${ }^{5}$ Áreas Prioritárias para Investimentos em Turismo são regiões que foram concebidas como destinos ou potenciais destinos em função de critérios como distância, máximo potencial de produto e marketing, densidade populacional, infra-estrutura e acesso, acomodação, ligação com iniciativa econômica nacional e áreas de importância estratégica nacional, com vista a criar uma plataforma espacial para garantir melhor planificação e alocação de recursos para o desenvolvimento do turismo em Moçambique (Moçambique, 2004). 
${ }^{6} \mathrm{O}$ distrito de Dondo, além de constituir um dos centros industriais da província de Sofala, é também um corredor frequentemente utilizados por transportadoras nacionais e internacionais que tem investimentos em Moçambique, assim passa pela EN1 caminhões que circulam pela África austral e pelo país. Todos automóveis não são autorizados a passar além da portagem em nenhum dos sentidos, por questões de segurança, sendo que a portagem fica fechada a partir das 9:00hrs da noite. Assim, maior parte dos camioneiros que ficam retidos na portagem passam a noite na cidade de Dondo.

Francisco Fransualdo Azevedo: Universidade Federal do Rio Grande do Norte, Natal, RN, Brasil.

Email: ffazevedo@gmail.com

Link para o currículo Lattes: http://lattes.cnpq.br/2719998085102847

Felicidade da Juliana Chicico: Escola Superior de Hotelaria e Turismo da Universidade Eduardo Mondlane, Maputo, Moçambique.

Email: chicico@gmail.com, felicidadedajuliana.chicico@gmail.com

Data de submissão: 31 de maio de 2012

Data de recebimento de correções: 20de novembro de 2012

Data do aceite: 20 de novembro de 2012

Avaliado anonimamente 